\title{
Open Services Innovation:The Case of BT in the UK
}

\author{
Carlos Eduardo Yamasaki Sato
}

\begin{abstract}
Open innovation was conceptualised by Chesbrough (2003, p. 34) using cases from the ICT (Information and Communications Technologies) sector, more specifically equipment and component suppliers such as Lucent, IBM and Intel. Subsequently, the vast majority of the case studies in open innovation emphasised innovation processes in goods-based firms, not in service firms. Open systems innovation was well known in the telecommunications industry well before Chesbrough's conceptualisation of open innovation. However, subsequent research has not paid much attention on its adoption by incumbent telecommunications operators. This paper investigates how open innovation was adopted by the incumbent telecommunications operator BT in the UK, using the case study as the research method. BT used open innovation as a management injunction to systematise innovation under a common framework to leverage and integrate technology and knowledge in order to address customer needs, and to change the way of thinking about innovation within BT.
\end{abstract}

Keywords: open innovation; service innovation; research \& development (R\&D); information and communications technologies (ICT); next generation network (NGN); public switched telephone network (PSTN); internet protocol (IP); voice over internet protocol (VolP).

University of Sussex, School of Business, Management and Economics, Science Policy Research Unit (SPRU), The Freeman Centre, Jubilee Building, Falmer, Brighton, East Sussex BNI 9SL, United Kingdom Phone: +44 (0)1273 873564; e-mail: c.e.y.sato@sussex.ac.uk

ISSN: 07 I8-2724. (http://www.jotmi.org)

Journal of Technology Management \& Innovation (c) Universidad Alberto Hurtado, Facultad de Economía y Negocios. 


\section{Introduction}

The literature on open innovation started privileging the supplier side (usually producers of manufactured goods) of the innovation process, where companies such as IBM, Intel and Lucent (as in Chesbrough (2003)) were used to illustrate their 'open' practices to create and capture value. Since then the concept of open innovation as a business practice has received much attention, and it has been diffused to other sectors besides ICT (see, for example, Gassman et al. (2010) and Huizingh (20II)). Case studies were done in firms such as P\&G (Dodgson, Gann, \& Salter, 2006), ItalCementi (Chiaroni, Chiesa, \& Frattini, 20II) and the Dutch materials company DSM (Kirschbaum, 2005).

More recently, open services innovation has been advocated as an important business practice in order to avoid the commoditization trap (Chesbrough, 20l I). The argument is to rethink the business as a service business and to figure out business models that can take better advantage of the commercialization of tangible goods. The examples (for large firms) range from product-based firms (Xerox and $\mathrm{GE}$ ) to service-based firms (KLM and Merrill Lynch) (Chesbrough, 20II).

The success of the acceptance and diffusion of the concept of open innovation does not seem to be because it was a new phenomenon in the market, but a phenomenon in the ICT sector that had been occurring for some time, but captured and conceptualised in a way that it could be meaningully communicated and translated to other context and sectors than ICT. However, within the ICT sector, few studies have addressed the world of service providers such as the incumbent telecommunications operators such as BT, which is plagued by strong competition, and desperate to create new paths for growth. The focus of attention has been usually within the ICT equipment and component suppliers as in Chesbrough (2003), mentioned earlier, and Ferrary (201 I), who discusses open innovation in the context of the telecommunications equipment industry, using comparative case studies of Lucent Technologies and Cisco Systems.

As competition from different parts of the industry emerges, threatening the traditional sources of revenues of incumbent telecom operators, and with the landscape becoming clearer about the convergence of markets, the traditional ways of introducing new products and services are no longer adequate to keep pace with the speed of change in the market. A platform strategy demands that the organisation adopts more open practices. By definition a platform strategy involves the ability of others to 'build' on the platform which means that the information necessary for interoperability and the capacity to interoperate needs to be provided to others. In addition, open means that the incumbent telecom operators are more inclined to collaborate externally not only in R\&D (Research \& Development), but also in the implementation of different business models for commercialisation. This happens because at the infrastructure level, the incumbent telecom operators have divested the equipment suppliers which were part of the vertical integration of more monopolistic times (Fransman, 1994). At the services level, the uncertainty about the future services and applications which will render revenues leads BT to look actively for external innovators and technologies which can be somehow combined with BT resources in the development of new services. Thus, incumbent telecom operators are reorganising their infrastructure and processes in order to increase the 'interaction surface' with third party firms.

The term innovation was originally devised to distinguish the process of invention from commercialisation (Freeman \& Soete, 1997). Invention and commercialisation can occur in the various stages of the innovation process, taking the linear model as a reference: closer to the original invention (i.e. closer to science and R\&D), during intermediate stages of developing products and services, and finally closer to the final customer (i.e. the final commercialisation). This is a modified view of the original linear model, where commercialisation is only a downstream activity. In this modified view, commercialisation can occur in intermediate stages of the model. Recent developments facilitate a more open strategy, where further mechanisms of external collaboration and access to external resources facilitate invention and commercialisation in the various stages of the innovation process. Thus, open innovation emphasises a more collaborative approach with external parties in the various stages of the innovation process.

This paper is concerned with how BT is reshaping its service innovation processes. The focus is the nature and consequences of open innovation practices as they are applied in a service company within the ICT sector (original sector explored by Chesbrough (2003), but here from a service firm perspective), changing the way BT innovates in the development of new services. The research question that guides this paper is: Is open innovation relevant to incumbent telecommunication operators (as large service firms)? If so, how is open innovation implemented?

The aim is to show how the concept of open innovation is implemented as part of the overall strategy being undertaken by BT. Open invention is primarily done through partnerships with academics from universities, and sometimes through direct interaction with customers at the level of the application of the technology. Open commercialisation happens through the business of integrated solutions in interaction with larger customers, and through initiatives like 
Web2IC that try to address smaller customers and the mass market. Web2IC was part of the BT2ICN initiative, where BT made available API (Application Programme Interface) for third party developers to access BT's network and to develop applications. It is the idea of opening the platform for external firms and developers. In 2008, BT acquired Ribbit, which overtook the Web2 IC initiative (Meyer, 2008). Although the focus is on BT, it is very likely that many of the ideas discussed here may be usable for other incumbent telecom operators. The analysis of open innovation at BT indicates that it is used as a framework to build a coherent innovation strategy, coordinating all innovation initiatives that have been occurring separately (and sometimes disjointedly) as a result of both top-down and bottom-up approaches. In other words, the usage of 'open innovation' as a management injunction at BT is one favouring a multiplicity of knowledge sourcing and development models, each of which needs to have a suitable business model, and all of which must be co-ordinated within the framework of creating a coherent environment, landscape, or eco-system.

\section{Research Methodology}

This paper is part of a broader research that investigated the strategies for business renewal of incumbent telecommunications operators. The research methodology was based on case study method and it was done in three stages. Stage I was the exploration phase where the context of the research problem and incumbent operators were investigated. One of the outcomes of this phase was to narrow the options down to BT as the main case study to be developed. Stage 2 was the phase of exploitation where more information about BT and the industry was gathered addressing the research questions on the three logics of technology, organisation and customer. Stage 3 served to further exploit the insights and propositions reached in phase 2 and attempted to confirm (or not) those propositions.

The evidence was obtained through documentary analysis and a large number of interviews. The research methodology is fully described in Sato (2014) and it is not included in this paper.

\section{Structure of the paper}

This paper is structured as follows. Section 2 contains a brief literature review highlighting the absence of case studies illustrating how open innovation is implemented in service firms in the ICT sector, in particular in incumbent telecommunications operators. Section 3 discusses the major changes in the philosophy of innovation within BT, and why and how the innovation strategy and processes needed to be changed. Section 4 shows the various initiatives of BT to implement the open innovation concept. Section 5 dis- cusses such initiatives and the innovation model pursued by $\mathrm{BT}$, and elaborates on the implications for incumbent telecom operators in general. Section 6 draws conclusions from this paper.

\section{Open Innovation and Services}

Open innovation has received much attention as it is an expression which captures several practices aimed at improving innovation performance through outside-in and inside-out transactions (Huizingh, 20I I). Although open innovation may entail a dichotomy 'open/closed', in practice it is deemed, unsurprisingly, as a continuum exhibiting different degrees of openness (Dahlander \& Gann, 2010) or not as a clear-cut, either-or concept (Lazzarotti \& Manzini, 2009; Trott \& Hartmann, 2009).

Initial cases of open innovation were within the ICT sector, within companies such as Lucent, IBM and Intel (Chesbrough, 2003), Nokia/mobile telephony (Dittrich \& Duysters, 2007), and Lucent/Cisco (Ferrary, 20I I). These researches emphasize the supply side of the innovation process. Other studies on open innovation were conducted across a range of industries and firms, such as P\&G (Dodgson et al., 2006; Huston \& Sakkab, 2006), Italcementi (Chiaroni et al., 20I I), DSM (Kirschbaum, 2005), bio-pharmaceutical industry (Bianchi, Cavaliere, Chiaroni, Frattini, \& Chiesa, 20II). Still the emphasis clearly seems to be on the suppliers of manufactured goods, and much less on services and service firms.

More recently, open innovation has been discussed in the context of services: open services innovation (Chesbrough, $20 \mathrm{II}$ ). Although the context is services, many examples are from product-based companies which are aggregating services to their portfolio. The argument is to increase the scope of activities, seeing the business as a service business. This argument is similar to the concept of service dominant logic (S.L. Vargo \& Lusch, 2004, 2008; S. L. Vargo, Lusch, \& Morgan, 2006; S.L. Vargo, Maglio, \& Akaka, 2008) and integrated solutions (A. Davies, 2003; Davies, 2004). However, there are cases of service companies such as KLM and Merrill Lynch (Chesbrough, 20II), which are originally service companies, not companies which try to find a better competitive advantage and position in the value stream between manufacturing and services (A. Davies, 2003; Wise \& Baumgartner, 1999).

In the ICT sector, little research has been done on open innovation in service firms, in particular incumbent telecom operators. However, Fransman (2002) had already identified the different approaches to innovation, i.e. open and closed innovation systems for the contemporary Infocommunications Industry and the Old Telecoms Industry. And subsequently, Chesbrough (2003) conceptualised open innovation 
in a way that could be captured and transmitted to a wider audience. The implementation of open innovation is an issue that needs to be better addressed (Huizingh, 20I I; Lichtenhaler, 20 I I; Mortara \& Minshall, 20 I I).

This brief literature review points out a main gap that is addressed in this paper: how open innovation is adopted/ implemented in incumbent telecommunications operators (as large service firms in the ICT sector). The next section starts to address this gap, dealing with the challenge of service innovation within $B T$.

\section{Changing the Way to Innovate in Services in BT}

Traditional innovation in complex network industries such as telecommunications involves a multiplicity of possible concerns about inter-operability, security and the robustness of the network. The heterogeneity of network equipment and the difficulties of the analogue technology involve much weaker capacities to isolate and process signals. With digital technology, network elements can become more modular. However, with increased opportunities for control and processing, the complexity of the overall system is somewhat reduced. For example, with digital technology, the control could be physically separated from the system being controlled, which was a significant advance in terms of network design and management (BT Senior Manager, Interview, November 2005). In a more general way, the changes in BT reflect the change in the belief that:'If it could be done it would be done thoroughly and therefore slowly' (Verwaayen, 2005). The approach to innovation seems to be very thorough and still very inward looking. For operating support systems, for example, such systems are still too complex for most customers (Ovum Senior Analyst, Interview, March 2007). This comment refers to suppliers of telecom equipment and systems such as Ericsson, Alcatel and others providing solutions to customers such as BT. However, it seems to be applicable to incumbent telecom operators, as BT also wants to have a 'more meaningful relationship with customers' (BT Senior Manager, Interview, March 2006). One of the ways to have more meaningful relationship with customers is to create simple-to-use/operate solutions that address specific customer needs. This is another significant influence of the overall strategy on BT's innovation strategy. Incumbent telecom operators and their suppliers are known for the robustness and reliability of their equipment and systems and, therefore, the network services they offer to very demanding customers. These are customers in, for example, the defence industry, traffic control and large multinational firms, where high degrees of reliability are necessary. This is a significant market for incumbent telecom operators, and they may approach such large and demanding customers in different ways (as it is the case with integrated solutions). However, there are those increasing number of applications where more interaction with consumers is necessary (consumers refer specifically to 'individuals acting largely outside of any business or other organisational context' (Moschella, 2003, p. xviii)), and where incumbent telecom operators may compete or cooperate with Internet-based giants such as Google and Yahoo, for the mass market. The approach to innovation of the incumbent telecom operators seems to be in need of change.

Incumbent telecom operators usually segment the market between consumers (i.e. the mass market) and business customers (i.e. enterprises and small, medium and large firms). For large business customers, BT is focusing on large multinational corporations and providing services based on needs identified with such customers. These services are provided through contracts and projects, in the form of integrated solutions. This is what is called contractual innovation (cf. Olleros, 2007). Included in this contractual innovation are those third party firms hired by BT to develop application on top of its platforms. There is however another space of innovation largely explored by Internet-based firms such as Google and Yahoo, and applications like Youtube, MySpace, Flickr, e-Bay,Wikipedia, etc. which are a part of the so-called Web 2.0, where users have the ability to contribute with contents. These Web 2.0 applications are becoming increasingly accessible due to the deployment of broadband, and as BT's CEO pointed out: 'In all cases our customers are saying that broadband will change the business model' (Verwaayen, 2005). This last type of innovation, made possible by the Internet (World Wide Web) and broadband, depends in a large extent to what is called non-contractual innovation (cf. Olleros, 2007).

The challenge for incumbent operators in the 2000's is in creating new products and services. It is not a numbers game anymore, where success is measured through the number of connections made (Verwaayen, 2005). As a result, existing jobs will migrate to other parts of the world due to the network economy, and due to the fact that a firm needs to find the right people for the right job. To illustrate this with an example, the top 250 BT executives hold 17 different passports between them (Verwaayen, 2005).A more diverse team is expected to favour innovation.

The platform strategy being deployed by BT at a higher level assumes that much of their internal resources can be redeployed, and value can be created by re-using existing resources and capabilities. To support the 're-use' approach, BT's CTO Matt Bross claims that 'probably the most misunderstood thing about BT2ICN is that my role has been to unlock what has already been embedded here' (Berris, 2005). The idea of 'unlocking what is already there' is the philosophy that permeates the organisation of innovation within BT. Matt Bross uses the concept of 'innovation contin- 
uum' to explain his points: 'innovation continuum comprises three elements, [I] discovery and research; [2] validate and articulate; and [3] execute. [...] These processes work to provide an open and honest approach to creating new developments (Berris, 2005). However, the concept of 'innovation continuum' used by BT is based on a linear model, and as such, it reproduces some of the problems encountered in the linear model, specifically the time and opportunity lost due to the long feedback time from execution to discovery and research. To minimise the feedback delay time, a set of aims and purposes are established for the teams to drive innovation worldwide. Global intelligence teams around the world are put in place in order to search and identify new trends and technologies that may impact BT's business. Finally, a team was established to analyse and translate the technological and economic jargon into a business case of products and services that can be commercialised (Berris, 2005). All these initiatives were put in place or enhanced in order to give a more coordinated and systematised approach to innovation.

Constructive criticism and tolerance to genuine failures (through a culture of trial and error) make the innovation environment more fluid. Several stages of the innovation process are exposed and subject to criticism. Considering innovation as the various processes from invention to commercialisation, it is possible to verify the degree of openness (in terms of external collaboration and access to external resources) in the various instances of invention (closer to R\&D) and commercialisation (closer to the contract with the customer or the purchase by the consumer). The customer focus strategy of BT enhances the commercial focus of innovation. BT's approach to innovation, in the view of one senior manager "changed [BT] from being technology driven to commercially driven' (Berris, 2005). This means that 'in the past BT aspired to be the most innovative in new technology. That changes into aspiring to be the world's best at leveraging technologies to the benefit of our customers and shareholders' (Berris, 2005). Leveraging technologies is consistent with the platform strategy of the next generation of telecommunications. This leveraging strategy is also favoured by the fact that most of the incumbent telecom operators have separated their network operations from the design and development of equipment and systems (Fransman, 2002).

To summarise BT's innovation strategy, it seems that the reorganisation of innovation is based on the idea of having a common framework that is shared within BT, showing how various parts are connected to it (Berris, 2005). BT is calling this reorganisation 'open innovation'. The next section investigates further into how BT is implementing its open innovation strategy.

\section{Open Innovation at BT}

BT, a traditional telecommunication operator in the UK, has been examining 'the process of innovation itself as they attempt to transform themselves and drive sustainable sources of value creation' (BT, 2006, p. 4). As part of this examination, BT is deploying what it calls 'open innovation'.

For BT, open innovation means that 'organisations can draw on external resources and best practices to complement the value of their own "internal" innovation assets - and achieve greater real returns on their overall investment in innovation' (BT, 2006, p. 6). 'Innovation itself is valued as a commodity that can be bought and sold, loaned, licensed, hedged and re-invested' (BT, 2006, p. 6). Products and services need to be delivered much faster than in the past. Traditional firms like BT were used to deliver a single or few set of products and services for a long time (usually years), for a definite set of customers (with no other significant choices). Now customers have more choice and certain services can last few months or even weeks or days. Thus, the capability to offer new services faster became too complex for just one firm to provide, relying on its internal R\&D and product development pipe.

With a high degree of technological choice among the various suppliers in the telecommunications market, the expectation of innovation is higher and incumbent firms, in order to sustain their growth and competitive advantage are not expected to innovate alone. In fact, they reached a point where external collaboration is needed to sustain growth and profitability. One of the arguments of the open innovation model is that large firms should do less R\&D and rely more on external partners to deliver new products and services. In the telecom industry it is known that this shift to less in-house R\&D by the incumbent operators was a reality by the end of 1995, when most of the R\&D performed for the infrastructure (network and its elements) was relegated to the specialist equipment providers (Fransman, 2002). During the 2000's, this pattern continued for BT and for other incumbent operators. Fransman (2002, p. 49) compares the R\&D expenditure as a percentage of sales of NTT, BT and AT\&T compared to suppliers, other (new entrant) operators and other industries.

In 2002, BT hired a new CTO, Matt Bross, who came from the USA with experience in a non-incumbent telecom operator, Williams Communications. He says that having never worked for an incumbent telecommunication network operator before is a positive, as he has been unafraid of breaking the boundaries and changing the innovation processes of BT (Berris, 2005). These attributes seem to be necessary to meet the challenge of the transition to NGN. Surely, implementing the new network is a very complex 
activity, which requires many skills in project management and systems integration. However, one central challenge is to change peoples' minds, behaviours and attitudes: people are accustomed to PSTN processes and resist changing to the new NGN-based processes (BT Senior Manager, Interview, November 2005). The PSTN processes are related to functional structure and clear end-services, and the NGN processes are related to platform multifunctional structure and enabling new services (frequently without having a clear idea of what services will be developed). BT's approach to innovation is changing the way the firm operates (BT Senior General Manager, Interview, March 2006). The resistance to change is understandable, since people may perceive change as a threat to the status quo and the benefits of change may not be clear for them.

As the BT CTO says: 'BT has always been innovative, but I believe we need to innovate the way that we innovate. [...] We have changed from being technologically driven to commercially driven. [...] In the past, [the focus was] on the invention of things. Now it's the real focus on the products [BT is] getting out of the marketplace' (Berris, 2005). 'Innovating innovation' is the same argument used by John Seely Brown in the foreword of the book by Chesbrough (2003) on open innovation. In order to survive, incumbent telecom operators like BT are trying to change the way in which they innovate, firstly by making innovation a top management level strategic issue, and then by putting in place not only mechanisms and processes to allow others to collaborate, but also actively seeking external partners to complement their internal innovation.

The revised innovation process that is being set up in BT involves exploring innovation worldwide by establishing global intelligence teams to identify and communicate new ideas. According to Bross, BT is moving from an internally focused to an open innovation model (Berris, 2005). These global teams are called innovation scouts (BT, 2006). As the BT CEO Ben Verwaayen says: 'Where we spend the $\_3$ billion [in R\&D and capital expenditure], how we spend it, yesterday or tomorrow, will make all the difference whether we can help others to innovate' (Verwaayen, 2005). That is the new mindset of 'open innovation' where the incumbent operator is trying to establish a platform that helps others to innovate. The incumbent operator does not perform all the tasks related to innovation.

Old models of innovation, based on internal R\&D-driven products and services pipelines are not agile enough to drive sustainable growth (BT, 2006). In this old model, IPRs (Intellectual Property Rights) continue to be internal resources, without much chance of being commercialised, i.e. sold to others in the event the IPR cannot be used internally to derive commercial value from products and services. The mind- set is to invest a larger amount of resources proportional to the results that the firm envisions obtaining, or in the words of BT CEO Matt Bross: 'This insular viewpoint dictates that the quantity of innovation an organisation can deliver correlates directly with the amount of resource invested' (BT, 2006, p. 3). As firms become larger in revenues, for example, every percentage of growth is increasingly harder to obtain by themselves as 'the number of new ideas that can be developed and brought to market - in other words the breadth of your innovation pipeline - is ultimately constrained by the size and wealth of a company's R\&D department' (BT, 2006 , p. 3).Although the size and wealth of a company's R\&D department is seen as a constraint, the problem seems to be that managing an ever larger R\&D effort increases more rapidly than its growth in scale leads to diminishing marginal returns in the delivery of effective solutions. Thus it is solving the problem of diminishing marginal returns rather than overcoming a fixed constraint of wealth that is important. In order to break this unsustainable model, BT has been examining 'the process of innovation itself as they attempt to transform themselves and drive sustainable sources of value creation' (BT, 2006, p. 4). These sustainable sources of value creation seem to be more interactive with external collaborators and resources, where costs are shared and value can be unlocked from any stage of the innovation process. Thus, $B T$ is engaged in transforming their R\&D as part of their innovation process.

As a way to enhance the interaction with external collaborators and resources, BT relies on innovation partners: BT customers, academic research partnerships (MIT, University of Cambridge, University College London, Stanford University and UC Berkeley), external venturing partners (in association with BT's New Venture Partners) and strategic business partnerships (e.g. HP, Microsoft and Intel) (BT, 2006). Research partnerships with universities, for example, may result in products and capabilities that it may not make sense for BT to take advantage of now, but a new venture can be formed in order to explore them. One example is a spinoff from BT called Psytechnics that develops software for measuring and monitoring voice and video quality in communication networks.

In brief, open innovation means that large corporations like BT are becoming more 'humble'. Instead of waiting for others to look to BT for their ideas and technologies, BT is actively looking for ideas outside its boundaries. For this purpose, BT has created three units: Innovation scouting teams; Innovation Central; and the advanced technology centre.

Innovation scouting teams operate in the USA, Asia and the Middle East in order to identify new technologies, business propositions and market trends. They search for new technologies and ideas, interacting with technology companies 
connected to venture capitalists, with start-up firms and BT suppliers. They ultimately present innovative ideas and technologies to development groups within BT (BT, 2006). With this active search of new technologies and ideas in different sources and markets, BT avoids the limitations of relating only to their existing suppliers as technology sources.

Innovation Central, championed at chairman level, is a new organisational unit with the mission to deliver a structured innovation process (BT, 2006). The idea here is to have an integrated process, with high-level sponsorship. The integrated process means that each area of BT is invited to contribute and avoids giving importance to one activity to the detriment of others. As Matt Bross puts it (Berris, 2005, p. 34) puts it:

The notion here is putting in place a set of processes that allows people who exist in each one of the different areas of BT to contribute, as opposed to have the pendulum swing and say, for example, it's all about the portfolio and forget about the management. Or it is all about the new customer care system, forget about the product development cycle.

This addresses an important point of having the sponsorship at the highest level of the corporation (as is emphasised in project management literature such as Kerzner (2006) and Meredith and Mantel (2006)) and the notion of 'integrated process'. Usually what is emphasised is how the different parts of the system fit together and what to do to accomplish it. However, little emphasis is put on the people who are doing that. As BT CTO Matt Bross argues: 'People make things work, boxes don't. The raw material is always people' (Berris, 2005, p. 34).

The advanced technology centre is responsible for prototyping and validating concepts from the idea stage to the commercial product (BT, 2006, Pp. 13-14). On the other hand, the centre can stop an initiative as soon as it proves unfeasible. The aim of the centre is to connect the global scouts and external collaborators with the internal product development teams.

These initiatives provide evidence of BT's commitment to transform their R\&D into a more open innovation strategy, introducing processes and teams to connect external and internal innovators and resources. The active search for new technologies in the external market also evidences a different mindset where BT recognises that it may not have all the resources and technologies to develop the next products and services. Finally, an important point of this strategy of open innovation is to place the responsibility of R\&D structure at chairman level. As important as the activity itself is the sponsorship at the appropriate level.

\section{BT's additional processes to access external innovation}

BT has been establishing several processes to interact with other firms and gain access to external innovation (BT, 2006):

- BT has published the BT Technology Journal since 1997, where researchers and managers from BT share their knowledge and vision with a wider community. This journal presents the concepts and ideas BT is using to deploy their networks, and it is a way for the BT R\&D people to publish their 'blue sky' research. It also contains information about patents granted to BT. This exposure of patents allows further possible commercialisation with external parties. However, these journals may be part of the IPR strategy management. By disclosing certain researches and results in the journal, BT reveals them to be current practice which makes it impossible for others to patent them. The journals may also disclose 'blue sky' research as a way of building claims for the originality of ideas for which patents may subsequently be issued. Finally, the disclosure of patents in such journals is not only a way to reward those who have devised the patents and offer commercialisation opportunities, it is also a way to reinforce BT's claims of originality for these patents and thus assist their defensibility if they are challenged. Whatever the motivations, journals increase the exposure to the external community, stimulating interactions and, sometimes preventing them.

- $\quad$ Partnership with universities. BT has strategic partnerships with MIT, the University of Cambridge and University College London. About 10\% of BT's research budget is divested through these partnerships and in 2006 BT was reported to have 36 core research activities with such academic partners, 23 of them within the UK. The partnership with academia helps to identify disruptive technologies; to work on products and services that may be in the market place within three to five years; and analyse the competitive landscape for telecommunications within five to ten years.

- $\quad$ Supporting postgraduate students and researchers. BT has an annual research fellowship programme, where researchers are selected to spend a limited period of time within BT for their academic research. Also, through the academic partnerships, academic researchers can stay in BT facilities conducting joint researches that render value to $B T$.

- Venture Capital.As of 2006, BT works closely with New Venture Partners (NVP) LLP. Firms are spun-off BT and both $B T$ and NVP fund the new ventures, having equities in such start-ups. As of 2006, BT launched eight start-up companies, leveraging BT's IPR portfolio. 
- $\quad$ Strategic business partnerships. BT has strategic partnerships with firms like HP, Microsoft and Intel to leverage technology for long term applications.

- $\quad$ Another source of external innovation and knowledge are the skilled people that BT is able to attract even from other industries or other segments of the market. Examples start with the top management like Ben Verwaayen (CEO) and Matt Bross (CTO). Other people came from IBM, from consulting firms (e.g.Accenture) and from software development companies (where BT has wanted to learn about the horizontal broadband applications).

The initiatives under the 'umbrella' of open innovation show the commitment of BT to transform its R\&D in order to interact more actively with external innovators and resources. Several of the initiatives mentioned above are not new ones, but it is intended that they be part of the coordination effort involving combining existing and new initiatives under the same 'umbrella', hence allowing both bottom-up and topdown innovation approaches to be more effective.

\section{Open Innovation Implications for BT}

Considering that innovation may be seen as the process from invention to commercialisation (Freeman \& Soete, 1997), it is important to verify what happens in the interfaces between invention and commercialisation, as the organisation which makes the invention may not commercialise it, creating various possibilities of purchasing technologies, products and ideas from different firms. This is the basis of the concept of open innovation (cf. Chesbrough, 2003). BT, for example, uses the concept of 'innovation continuum' to highlight its end-to-end process (Figure I).

In expanding the concept of innovation and considering it as an end-to-end process, innovation may seen as composed by invention, integration and commercialisation, where invention is predominantly on the supplier's side; integration is represented by architecting and implementing the network (the infrastructure level), highly dependent on project capabilities; and commercialisation is represented by operating, productising and distributing the products and services. The locus of innovation is moving to the right edge as the processing power of consumer devices and competition increases. It is increasingly feasible to come up with a new application, select and discard it without going into bankruptcy. The cost of failure tends to decrease. Thus, the leftmost processes in Figure I representing a technology driven company become much more about how to leverage those technologies to the benefit of customers. This makes the issue one of not only concentrating on internal processes, but also on managing boundary processes to achieve such an aim. The right timing to deploy the new infrastructure and to deliver new services (decreasing delivery time, for example) becomes an important part of the innovation strategy. So, including the timing dimension, the innovation process encompasses, besides invention and commercialisation, integration with the appropriate timing.

From the perspective of incremental-radical innovation, taking the voice-only service as the existing product of incumbent fixed-line telecommunications operators, the NGN contributes to the commoditisation of this service, which is still used and purchased but also bundled with other services. The increased capacity of IP networks makes it possible to resell bandwidth for various applications, and then: (i) regulators choose not to allow BT or other network operators to discriminate in favour of particular services; (ii) network operators must offer high capacity data transmission at tariffs which attract customers; and (iii) customers can disaggregate and sell this capacity in the form of voice grade lines (services with low or absent quality-of-service standards). The ability of network operators to create scarcity of network capacity is no longer possible due to the combination of these factors. A discussion about the dialectic of scarcity-abundance of communication and information access and its implications can be found in Mansell (1999). The business model for the long distance voice tariff becomes obsolete and, as a consequence, voice-only services generate less and less revenues. There is a general consensus that broadband is cannibalising the incumbents' businesses, and there is an increasing pressure of Internet companies like Skype, Google and Yahoo with their VolP (Voice over Internet Protocol) services, pressing prices down and challenging incumbent business models.

The fact that BT, as an incumbent, is embracing a radical innovation in a more radical way may be partly explained by the company's strategic leadership. BT changed its top management significantly at the beginning of the 2000s, a few years before announcing BT2ICN. The main changes seem to have been in the CEO and CTO positions, which were assumed by company outsiders. This may have accelerated the decision-making process to deploy BT2ICN.

In terms of organisational capabilities, the transition to NGN is 'competence-destroying, in relation to the PSTN technology. However, most of the incumbent operators are making the transition in an 'incremental' fashion that will take years to complete. In large systems such as the telecommunication networks, there is much inertia to change (Hughes, 1987), and it may take much more time to change than in the mass market products context. So, incumbents have more time to position themselves in response to the 'radical' innovation. The term 'disruptive' is being overused in the telecom industry to express the impact of VolP (Voice over Internet Protocol) on the incumbent telecommunications operators 
business. VolP services provided by firms like Skype do have a disruptive trajectory. However, unlike other markets analysed by Christensen (Christensen, 1997; Christensen, Johnson, \& Rigby, 2002; Christensen \& Overdorf, 2000; Christensen \& Raynor, 2003), the transformation in telecommunications networks is over a large and complex system, in a regulated environment and with high inertia. Due to this inertia, incumbents have time to adapt to the new technology and their business seems not to be destroyed. Also, incumbents have the option to partner or even buy Internet companies, minimise the effect of VolP on their core business, and learn. For example, BT partnered with Yahoo in 2004 and started offering VolP, but with no reduction in prices. BT Communicator was part of a partnership with Yahoo. The service was terminated in 2006 and replaced by BT's own service, BT Softphone.After the purchase of Skype by E-Bay in 2005, BT started to offer a VolP service that was even cheaper than Skype's. On the other hand, although incumbents may have time to adapt to the new technology, the inertia in the telecommunications environment is uneven. Other players such as the cable TV providers and smaller network operators can move faster and fill in the market gaps left by BT. Thus, by the time BT (and other incumbents) finishes the upgrade of their network, their competitive advantage may be significantly reduced, or even worse, overcome.

Innovation in incumbent telecommunications operators cannot be analysed only within the firm. As these operators are large adopters of technologies, the selection of suppliers to work with is of the highest importance. Matt Bross, CTO of BT Group, characterises the innovation 'continuum' as composed of three elements: (i) research and discovery; (ii) validate and articulate; and (iii) execute (Berris, 2005). From this perspective, the innovation continuum may not happen within one firm; it happens more frequently across boundaries, from the invention, through to the supplier's network and the suppliers themselves, to the service providers, the distribution and to the final customers. The challenge is that innovation locus is moving closer to the customer. BT and other service providers are starting to invest in a new network to provide 'new services' without knowing exactly what these services are going to be. The new services dilemma breaks the paradigm of control and predictability: the willingness to know how things will end before they begin.

Although BT, as a large incumbent fixed-line telecom operator, is innovating aggressively in transforming its network, this is not happening at the same pace in other incumbents in Europe and throughout the world. Interviewees from other incumbent operators say that what BT is doing is 'too radical' for their context.Also, in this context, as the telecom operators are not producers of technology, they innovate to the extent that their suppliers innovate. The key innovation factor for the operators is the selection of the most appropriate partners. All of the selected BT partners for the BT2ICN project are large companies: Siemens, Cisco, Alcatel, Ericsson, Fujitsu, Ciena, Lucent and Huawei. The smallest is Ciena. However, the majority of these large firms are partnering with smaller firms to supply their solution to BT. As the telecommunications networks are large and complex systems, where some components are CoPS (Complex Products and Systems), the key to innovation and success in the market is to combine its core capabilities with those of smaller firms in order to deliver complete, end-to-end solutions to sophisticated and demanding business customers. Thus, in this context, large firms and small firms partner with each other to innovate. It is true however that the IP technology was first developed by smaller, non-incumbent firms of the telecommunications market. Sonus was one of the firms founded in the late 1990s to take advantage of the emergence of IP technology.

The innovation process at BT is still much based on the linear model. Although this presents several limitations, the emphasis is on opening the various phases (e.g. according to Figure I, inventing, architecting, implementing, operating, productising and distributing) of the process to interaction and collaboration to external innovators and resources. One major implication is the need to understand the whole innovation process, not only the early phase of invention and later stages of commercialisation, but also the intermediate integration and timing issues. This leads to initiatives to change the internal organisation and processes to deal with interactions with the external environment. The open innovation at BT is one of such initiatives focusing mostly on the early stages of the process, closer to invention of new technologies.

\section{Conclusions}

The main conclusions of this paper are: (i) BT is moving to a more open innovation model, collaborating and allowing collaboration with external partners; and (ii) open innovation is a management injunction which BT is using to systematise innovation under a common framework to leverage technologies and knowledge to address customer needs, and to change the way of thinking about innovation within BT.

The response of BT to survive the market convergence/ competition in services and the technological change with the massive adoption of IP (Internet Protocol) technology is based on redesigning its innovation processes by means of higher levels of openness and collaboration with third party firms and customers.

BT is changing the way that it has been innovating. Innovation has become a highly regarded activity championed at chairman level. Also BT is actively seeking external partners, 
not being mainly focused on its existing suppliers. The existing suppliers play a major role in building the infrastructure and transferring the new accomplishments to BT. However, that is not enough anymore. The service layer has become much more dynamic. There is an increasing effort to decouple the infrastructure from the service layer. The absence of certainty (or any clear idea) as to what services will render the future profits and growth needed by BT requires a new mindset for developing new services. For BT, this new mindset is based on opening network interfaces to external collaboration, following a platform strategy. However, just opening interfaces is not enough. BT is actively seeking new ideas and technologies from external firms and working actively to diffuse those ideas and technologies within its own development teams.

By actively searching new ideas and technologies, incumbent firms like BT diminish the impact of potential disruptive technologies. The term 'active search' by incumbent providers also implies a different and more humble attitude towards innovation: incumbents cannot do it alone any more. The establishment of processes which depend on discovering new ideas and technologies, not only depending on existing suppliers becomes important. Existing suppliers of BT understand mostly about infrastructure, and less about services.

The infrastructure as a platform based on IP supports the strategy of establishing the innovation structure championed at chairman level and that embraces the whole company. The IP as a common technology from which it is possible to deliver voice, data, video, and mobility services with different types of contents allows incumbent operators to seek for internationalisation (new markets) with a more structured approach.

It can be noted that one important evolution of BT in the transition to NGN is the approach to innovation. The creation of Innovation Central championed at chairman level in order to have a company-wide structure for innovation is one sign of the importance given to it.

In the end, BT2ICN is the effort made by $\mathrm{BT}$ to acquire the features, skills and processes to compete with Internet software-based firms (like Skype, Google and Yahoo) while strengthening its position in infrastructure-based services. BT is making this transformation by building an ICT platform, based on IP-based infrastructure and APIs (Application Programme Interfaces) and SDKs (Software Development Kits) in the applications level.

The challenge is not only in the service itself, but also in the approach to innovation, i.e. how new services are developed. The monolithic, internal and complex approach of incum- bent operators is not enough anymore. The approach tends to be more open to external collaboration throughout the various stages of the innovation process.

How 'generalisable' is the open innovation of BT to other incumbent operators? Preliminary investigations indicate that open innovation has wider application and implications in the telecommunications industry. The platform strategy and the needs of external collaboration are becoming largely diffused throughout the telecommunications industry. However, external collaboration is not something new in the context of incumbent telecommunications operators, and the issue of control remains a major theme of debate. External collaboration is necessary, but incumbent telecom operators are still very reluctant to abandon the centralised control of networks and services. Customer choice is evolving, but with the underlying assumption that the incumbent telecom operator chooses what the customer may choose. 


\section{References}

BERRIS, J. (2005). Open and Honest Innovation. Global Telecoms Business, Sept/Oct 2005, 32-34.

BIANCHI, M., Cavaliere,A., Chiaroni, D., Frattini, F., \& Chiesa, V. (20II). Organisational modes for Open Innovation in the bio-pharmaceutical industry: An exploratory analysis. Technovation, 3I (I), 22-33.

BT. (2006). Embracing Open Innovation: A new approach to creating sustainable value. Retrieved 23 July 2006, 2006

CHESBROUGH, H. (2003). Open Innovation: The New Imperative for Creating and Profiting from Technology. Massachusetts: Harvard Business School Press.

CHESBROUGH, H. (20I I). Open Services Innovation: Rethinking Your Business to Grow and Compete in a New Era. San Francisco: Jossey-Bass.

CHIARONI, D., Chiesa, V., \& Frattini, F. (20II). The open innovation journey: how firms dynamically implement the emerging innovation management paradigm. Technovation, $31(1), 34-43$.

CHRISTENSEN, C. M. (1997). The Innovator's Dilemma: When New Technologies Cause Great Firm to Fail. Massachusetts: Harvard Business School Press.

CHRISTENSEN, C. M., Johnson, M.W., \& Rigby, D. K. (2002). Foundations for Growth: How to Identify and Build Disruptive New Businesses. MIT Sloan Management Review, 43(3), 22-3I.

CHRISTENSEN, C. M., \& Overdorf, M. (2000). Meeting the Challenge of Disruptive Change. Harvard Business Review, March-April, 67-76.

CHRISTENSEN, C.M., \& Raynor, M.E. (2003).The Innovator's Solution: Creating and Sustaining Successful Growth. Massachusetts: Harvard Business School Press.

DAHLANDER, L., \& Gann, D. (2010). How open is innovation? Research Policy, 39(6), 699-709.

DAVIES, A. (2003). Are Firms Moving "Downstream" into High-Value Services? In J. Tidd \& F. M. Hull (Eds.), Service Innovation: Organizational Responses to Technological Opportunities \& Market Imperatives. London: Imperial College Press.
DAVIES, A. (2003). Integrated solutions: the changing business of systems integration. In A. Prencipe, A. Davies \& $M$. Hobday (Eds.), The Business of Systems Integration (pp. 333368). Oxford: Oxford University Press.

DAVIES, A. (2004). Moving base into high-value integrated solutions: a value stream approach. Industrial and Corporate Change, I3(5), 727-756.

DITTRICH, K., \& Duysters, G. (2007). Networking as a Means to Strategy Change:The Case of Open Innovation in Mobile Telephony. The Journal of Product Innovation Management, 24(6), 510-521.

DODGSON, M., Gann, D., \& Salter, A. (2006). The role of technology in the shift towards open innovation: the case of Procter \& Gamble. R\&D Management, 36(3), 333-346.

DUNBAR, D. (2005). Building an Infrastructure for 2 Ist Century Networks

FERRARY, M. (20I I). Specialized organizations and ambidextrous clusters in the open innovation paradigm. European Management Journal, 29(3), I8I-192.

FRANSMAN, M. (1994). AT\&T, BT and NTT: The role of R\&D. Telecommunications Policy, I8(4), 295-305.

FRANSMAN, M. (2002). Telecoms in the Internet Age: From Boom to Bust to...? Oxford: Oxford University Press.

FREEMAN, C., \& Soete, L. (1997). The Economics of Industrial Innovation (3rd ed.). London: Pinter.

GASSMAN, O., Enkel, E., \& Chesbrough, H. (20I0).The future of open innovation. R\&D management, 40(3), 2I3-22I.

HUGHES, T. P. (1987). The Evolution of Large Technical Systems. In W. E. Bijker,T. P. Hughes \& T.J. Pinch (Eds.), The Social Construction of Technological Systems. Cambridge, MA:The MIT Press.

HUIZINGH, E. K. R. E. (20I I). Open innovation: State of the art and future perspectives. Technovation, 3I(I), 2-9.

HUSTON, L., \& Sakkab, N. (2006). Connect and develop: inside Procter \& Gamble's new model for innovation. Harvard Business Review, 84(3), 58-66.

KERZNER, H. (2006). Project Management: A Systems Approach to Planning, Scheduling and Controlling (9th ed.). Hoboken, New Jersey: John Wiley \& Sons, Inc. 
KIRSCHBAUM, R. (2005). Open innovation in practice. Research-Technology Management, 48(4), 24-28.

LAZZAROTTI, V., \& Manzini, R. (2009). Different modes of open innovation: a theoretical framework and an empirical study. International Journal of Innovation Management, I3(4), 6I5-636.

LICHTENHALER, U. (20I I). Open innovation: past research, current debates, and future directions. Academy of Management Perspectives, 25(I), 75-93.

MANSELL, R. (1999). New media competition and access: the scarcity-abundance dialectic. New media and society, I(2), I55-I82.

MEREDITH, J. R., \& Mantel, S. J. (2006). Project Management: A Managerial Approach (6th edition ed.). USA: John Wiley \& Sons, Inc.

MEYER, D. (2008). BT guns for Android and Skype with Ribbit buy. ZDNet UK.

MORTARA, L., \& Minshall, T. (20I I). How do large multinational companies implement open innovation? Technovation, 3I(I0-II), 586-597.

MOSCHELLA, D. (2003). Customer-driven IT: how users are shaping technology industry growth. Boston, Massachusetts: Harvard Business School Press.

OLLEROS, F. X. (2007). The Power of Non-Contractual Innovation. International Journal of Innovation Management, II(I), 93-II3.

SATO, C. E.Y. (20I4). Platform Leadership of Incumbent Telecommunications Operators: the Case of BT 21 st Century Network (BT2ICN). International Journal of Innovation Management, 18(2), 37 pages.

TROTT, P., \& Hartmann, D. (2009). Why 'Open Innovation' is Old Wine in New Bottles. International Journal of Innovation Management, I3(4), 7I5-736.

VARGO, S. L., \& Lusch, R. F. (2004). Evolving to a New Dominant Logic for Marketing. Journal of Marketing, 68(January 2004), I-I7.

VARGO, S. L., \& Lusch, R. F. (2008). Service-dominant logic: continuing the evolution. Journal of the Academy of Marketing Science, 36, I- 10.
VARGO, S. L., Lusch, R. F., \& Morgan, F.W. (2006). Historical Perspectives on Service-Dominant Logic. In S. L.Vargo \& R. F. Lusch (Eds.), The Service-Dominant Logic of Marketing: Dialog, Debate, and Directions (pp. 29-42). New York: M. E. Sharpe, Inc.

VARGO, S. L., Maglio, P. P., \& Akaka, M. A. (2008). On value and value co-creation: $A$ service systems and service logic perspective. European Management Journal, 26, I45- 152.

VERWAAYEN, B. (2005). Global Telecoms Business, Sept/ Oct 2005, n. 82, p. 12.

WISE, R., \& Baumgartner, P. (1999). Go downstream: the new profit imperative in manufacturing. Harvard Business Review(September-October), I33-14I. 